Article

\title{
Acute and Subacute Toxicity and Cytotoxicity of Opuntia Dillenii (Ker-Gawl) Haw. Seed Oil and Its Impact on the Isolated Rat Diaphragm Glucose Absorption
}

\author{
Mohamed Bouhrim ${ }^{1}$, Salima Boutahiri ${ }^{2,3}$, Loubna Kharchoufa ${ }^{1}$, Hamza Mechchate ${ }^{4, *(D)}$, \\ Omkulthom Mohamed Al Kamaly ${ }^{5, *}$, Ali Berraaouan ${ }^{1}$, Bruno Eto ${ }^{6}$, Abderrahim Ziyyat ${ }^{1}$, Hassane Mekhfi ${ }^{1}$, \\ Abdelkhaleq Legssyer ${ }^{1}$, Mohammed Aziz ${ }^{1}$ and Mohamed Bnouham ${ }^{1, *}$
}

1 Laboratory of Bioresources, Biotechnology, Ethnopharmacology and Health, Faculty of Sciences Mohammed First University, Oujda B.P. 717, Morocco; mohamed.bouhrim@gmail.com (M.B.); 1.kharchoufa@ump.ac.ma (L.K.); a.berraaouan@gmail.com (A.B.); ziyyat@yahoo.fr (A.Z.); hmekhfi@yahoo.fr (H.M.); alegssyer@yahoo.fr (A.L.); azizmo5@yahoo.fr (M.A.)

2 Univ. Lille, University of Liège, University of Picardy Jules Verne, JUNIA, UMRT 1158 BioEcoAgro, Specialized Metabolites of Plant Origin, F-59000 Lille, France; boutahirisalima@gmail.com

check for

updates

Citation: Bouhrim, M.; Boutahiri, S.; Kharchoufa, L.; Mechchate, H.; Mohamed Al Kamaly, O.; Berraaouan, A.; Eto, B.; Ziyyat, A.; Mekhfi, H.; Legssyer, A.; et al. Acute and Subacute Toxicity and Cytotoxicity of Opuntia Dillenii (Ker-Gawl) Haw. Seed Oil and Its Impact on the Isolated Rat Diaphragm Glucose Absorption. Molecules 2021, 26, 2172. https://doi.org/10.3390/molecules 26082172

\section{Academic Editors:}

Alessandro Attanzio and Luisa Tesoriere

Received: 7 March 2021

Accepted: 6 April 2021

Published: 9 April 2021

Publisher's Note: MDPI stays neutral with regard to jurisdictional claims in published maps and institutional affiliations.

Copyright: (C) 2021 by the authors Licensee MDPI, Basel, Switzerland. This article is an open access article distributed under the terms and conditions of the Creative Commons Attribution (CC BY) license (https:// creativecommons.org/licenses/by/ $4.0 /)$.
3 Research Team on the Chemistry of Bioactive Molecules and Environment, Laboratory of Innovative Materials and Biotechnology of Natural Resources, Faculty of Sciences, Moulay Ismail University, Meknes, Zitoune Meknes B.P. 11201, Morocco

4 Laboratory of biotechnology, Environment, Agri-Food, and Health (LBEAS), Faculty of Sciences, Dhar El Mahraz, Sidi Mohamed Ben Abdellah University (USMBA), Fez B.P. 1796, Morocco

5 Department of Pharmaceutical Sciences, College of Pharmacy, Princess Nourah Bint Abdulrahman University, Riyadh 11564, Saudi Arabia

6 Laboratories-TBC, Faculty of Pharmaceutical and Biological Sciences, B.P. 83 Lille, France; titisfrance@gmail.com

* Correspondence: Hamza.mechchate@usmba.ac.ma (H.M.); omalkmali@pnu.edu.sa (O.M.A.K.); mbnouham@yahoo.fr (M.B.)

Abstract: This study aims to assess the safety of the Opuntia dillenii (Ker-Gawl) haw. seed oil (ODSO) and its effect on the glucose absorption activity of the isolated rat hemidiaphragm. This oil's safety was studied by exploring its acute (doses $1,3,5$, and $7 \mathrm{~mL} / \mathrm{kg}$ ) and subacute (doses 1 and $2 \mathrm{~mL} / \mathrm{kg}$ ) toxicities in albino mice and Wistar rats, respectively. The safety of the ODSO was also assessed by studying its effect on the HepG2 cell viability in vitro. The effect of ODSO, or combined with the insulin, on the glucose absorption activity of isolated rat hemidiaphragm was evaluated at the dose $1 \mathrm{~g} / \mathrm{L}$ in vitro. The results demonstrated the safety of ODSO. Indeed, this study showed that this oil does not produce any mortality or signs of toxicity after the single-dose administration in mice. Additionally, the daily intake of the ODSO during four weeks does not induce a significant variation in the biochemical parameters and body weight of rats compared with the control group. Besides, the cell viability of HepG2 did not change in the presence of ODSO. On the other hand, the ODSO increased the glucose absorption activity of the isolated rat hemidiaphragm, and this activity was significantly enhanced when combined with insulin. This study confirms, on one side, the safety of this oil and its efficacy and, on the other side, encourages its potential use as a complement to treat diabetes.

Keywords: acute toxicity; subacute toxicity; cytotoxicity; glucose absorption; hemidiaphragm; Opuntia dillenii; medicinal plant; diabetes

\section{Introduction}

Prickly pear Opuntia dillenii (Ker-Gawl) Haw., located in the west and northeast Morocco, is a species from the Cactus family. Its fruit is eaten mostly in fresh fruit form, and it is used to control diabetes in folk medicine [1]. Many studies investigated the toxicological and biological effect of the pear, juice, and cladode of $O$. dillenii, but a few 
were interested in the seed oil's nutritional benefit and biological activities. The analyzed seed oil's components demonstrated that it contains considerable amounts of linoleic acid and sterols (unsaturated fatty acids), such as $\beta$-sitosterol and the presence of $\gamma$-tocopherol (vitamin E) [2]. Additionally, the oil is characterized by the presence of other substances such as phenols, well known for their health benefit $[3,4]$. Several kinds of research on this plant's fruit seed oil have shown that it has numerous activities such as antioxidant [5], hepatoprotective [6], antilipidemic, antidiabetic, and antidiabetogenic [7,8].

Herbs have been commonly employed as the primary prevention method to treat diseases since ancient times $[9,10]$. Today, botanical medicine is becoming increasingly widespread worldwide, particularly in developing countries with a plethora of medicinal plants highly abundant, affordable, and accessible. Although the promising therapeutic potential of these plants' use has been shown, there is still concern not only about their use but also about their safety [11]. In Moroccan culture, in particular, medicinal plants are commonly considered healthy or of low toxicity, because of their lengthy traditional usage [12-14].

Like medicines, extracts from medicinal plants have shown remarkable therapeutic potential, and they were proven not to be harmless products. The use of plants for therapeutic purposes must be made in a rational and controlled manner to avoid side effects that may even lead to the individual's death. In this context, assessing the biological effects of herbal extracts must necessarily begin with the assessment of their general toxicity. Following the experimental process of preclinical studies, the evaluation of the general toxicity of a new substance (an extract in our case) is imperative in an acute manner, subacute and chronic, while varying the follow-up period and the frequency of administration of the doses to be tested [15].

Antidiabetic medicinal plants are not free from toxicity, as demonstrated in a study conducted by Bnouham et al. (2002), in which they have compiled a list of 94 species of antidiabetic plants, including 17 toxic species. Although the study indicates that toxicity is generally related to the administration route [16]. Diabetes mellitus is a chronic metabolic disturbance marked by a disorder in the metabolism of carbohydrates, proteins, and lipids, which leads to an increased blood sugar level. It is due to a failure in insulin secretion by the pancreas or peripheral cells' response to the insulin effect. Insulin, which is a hypoglycemic hormone secreted by the $\beta$ cells of Langerhans islets, is considered vital for controlling blood glucose concentration by facilitating glucose absorption and metabolism by peripheral tissues [17]. The long-term consequences of untreated diabetes mellitus may extend to microvascular and macrovascular complications (neuropathy, kidney disease, retinopathy, and vascular diseases). In the untreated state, people with diabetes are characterized by increased hepatic glucose production and decreased glucose absorption in adipose tissue and muscles, hence the need to treat and control this disease [17]. In a study by Bouhrim et al., the antidiabetic effect of Opuntia dillenii (Ker-Gawl) haw. seed oil (ODSO) is shown by its ability to regulate the disorder of biochemical parameters related to carbohydrate metabolism. ODSO showed a hypoglycemic effect during the four weeks of treatment in diabetic rats. In the same study, ODSO increased the level of hepatic glycogen and decreased glucosuria in this animal model of diabetes. Taking into account that the animal model of diabetes used in this study is characterized by partial destruction of pancreatic beta cells and not insulin resistance, it could be that ODSO stimulates peripheral tissues to store glucose or potentiates the effect of insulin [7]. Skeletal muscle is the central tissue to use blood glucose and the key focus tissue for insulin action. Insulin improves the skeletal muscle's glucose uptake by raising the functional glucose transfer molecule (GLUT-4) in the plasma membrane [18]. For in vitro peripheral glucose uptake analysis, calculating glucose content in the rat hemidiaphragm is a commonly used and valuable technique [18]. This work aims to evaluate the safety of the ODSO and investigate its effect on the glucose absorption activity of the isolated rat hemidiaphragm to indicate a potential use in the treatment of diabetes. 


\section{Results}

\subsection{Acute Toxicity}

The results of this acute toxicity test showed that ODSO is not toxic even at $7 \mathrm{~mL} / \mathrm{kg}$ and also did not exhibit any signs of toxicity (diarrhea, vomiting, abnormal mobility, etc.) or mortality during the entire surveillance period.

\subsection{Subacute Safety of Opuntia Dillenii Seed Oil}

\subsubsection{Effect of ODSO on Hepatic Enzymatic Biomarkers (ALT, AST, and ALP)}

The daily ODSO administration effect during four weeks of treatment on liver function is shown in Figure 1. Daily administration of ODSO at a dose of 1 and $2 \mathrm{~mL} / \mathrm{kg}$ during the 30 days did not cause any significant variation in the level of hepatic biomarkers, which are the hepatic transaminases alanine aminotransferase (ALT) (A), aspartate aminotransferase (AST) (B), and alkaline phosphatase (ALP) (C) in comparison with the control group.

(A)

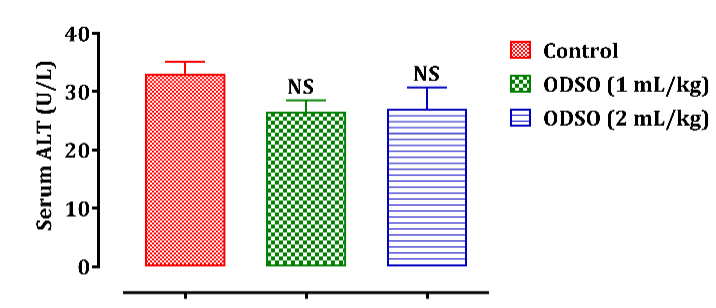

(B)

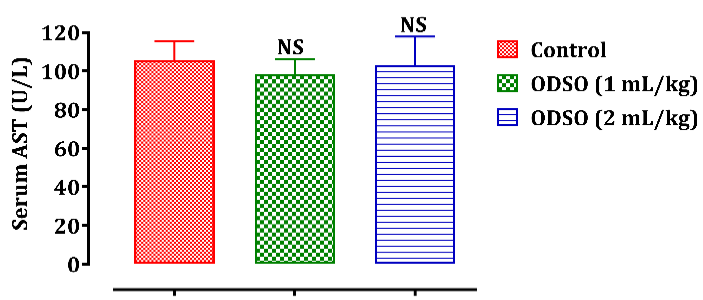

(C)

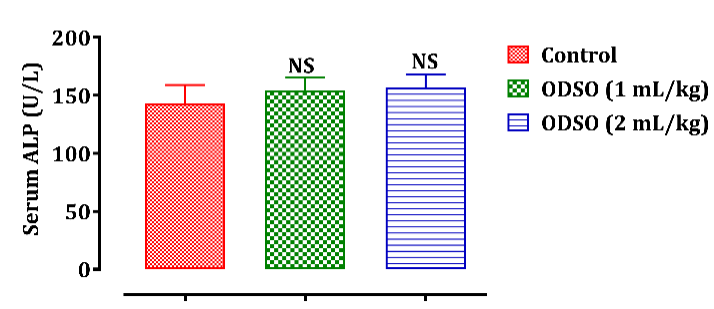

Figure 1. Oral administration effect of ODSO on ALT (A), AST (B), and ALP levels (C) in normal rats. Values are means $(n=6) \pm$ SEM. NS: Not significant compared to the control, ODSO: Opuntia dillenii seeds oil; ALT: Alanine transaminase AST: aspartate aminotransferase ALP: alkaline phosphatase.

\subsubsection{Effect of ODSO Administration on Plasma Bilirubin}

The variation in plasma bilirubin content depending on the administration of ODSO is shown in Figure 2. Indeed, the total (A) and direct (B) bilirubin levels in rats treated with ODSO (1 and $2 \mathrm{~mL} / \mathrm{kg}$ ) are similar to those in the control group.

\subsubsection{Effect of ODSO Administration on Lipid Profile}

The long-term administration of ODSO and its effect on rats' lipid profile is shown in Figure 3. No significant changes were caused in plasma total cholesterol (A), triglyceride (B), HDL (High-density lipoprotein) (C), and LDL (Low-density lipoprotein) (D) levels in rats after daily administration of ODSO $(1$ and $2 \mathrm{~mL} / \mathrm{kg})$ compared to the untreated control group. 
(A)

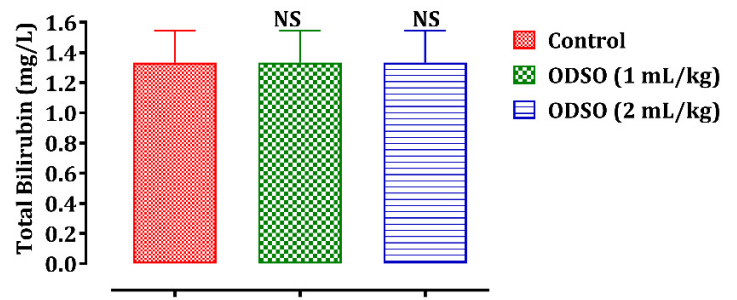

(B)

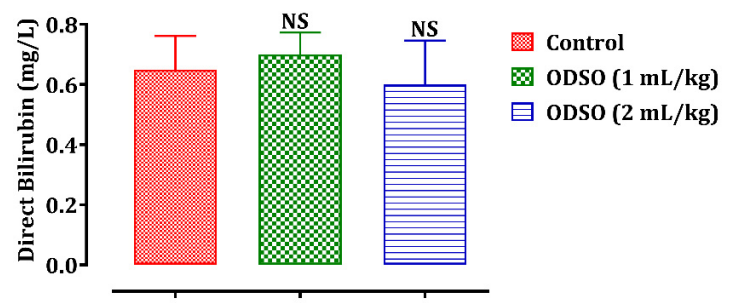

Figure 2. Oral administration effect of ODSO (1 and $2 \mathrm{~mL})$ on total (A) and direct (B) bilirubin levels in normal rats. Values are means $(n=6) \pm$ SEM. NS: Not significant compared to the control, ODSO: Opuntia dillenii seeds oil.

\section{(A)}

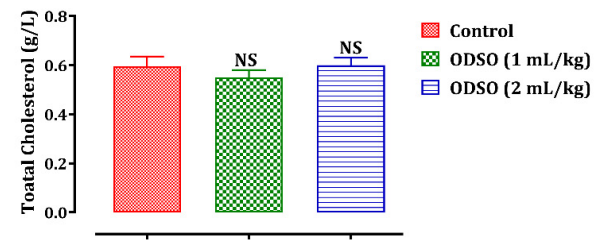

(B)

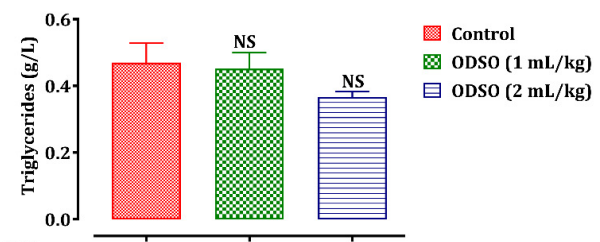

(C)

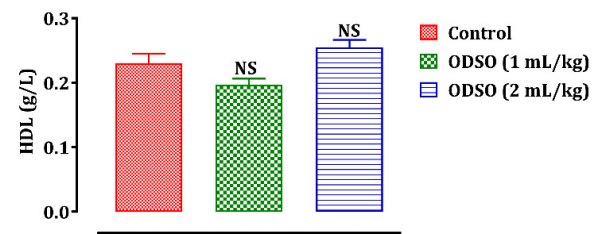

(D)

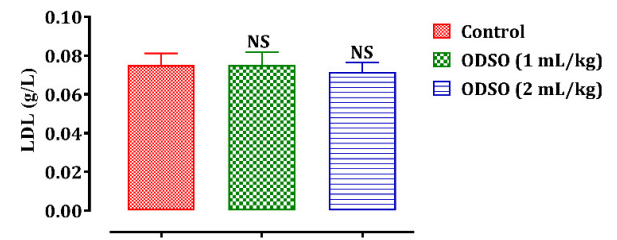

Figure 3. Oral administration effect of ODSO on plasma total cholesterol (A), triglycerides (B), HDL (C), and LDL (D) levels in normal rats. Values are means $(n=6) \pm$ SEM. NS: Not significant in comparison with the control, ODSO: Opuntia dillenii seeds oil; HDL: High-density lipoprotein; LDL: Low-density lipoprotein. 


\subsubsection{Effect of ODSO on Total Protein and Blood Sugar}

Blood glucose and total plasma protein levels were also quantified to demonstrate the safety of ODSO in the long term (Figure 4). The daily gavage of rats with ODSO (1 and $2 \mathrm{~mL} / \mathrm{kg}$ ) for four weeks did not induce any significant variation in these two plasma parameters-total proteins (A) and blood sugar (B) - in comparison with the control group.

(A)

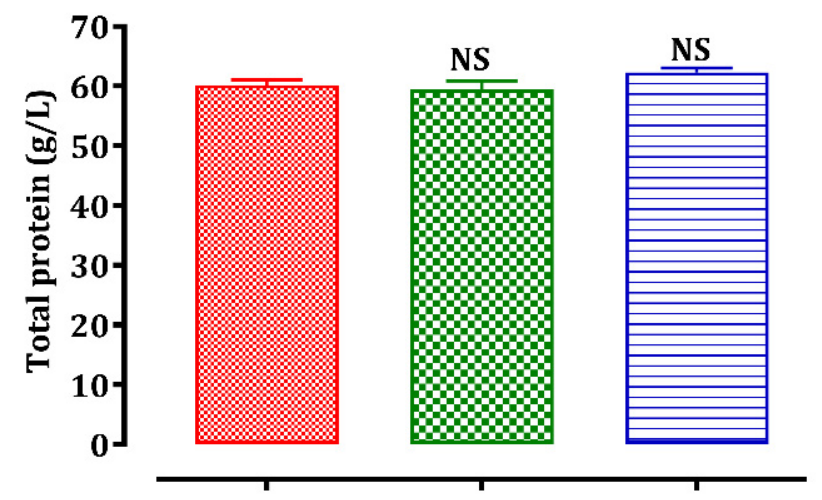

Control

ODSO (1 mL/kg)

ODSO $(2 \mathrm{~mL} / \mathrm{kg})$

(B)

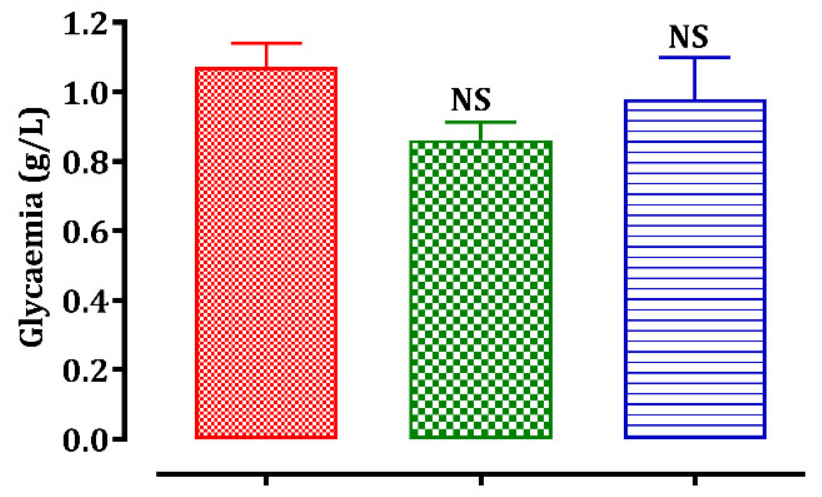

Control
ODSO $(1 \mathrm{~mL} / \mathrm{kg})$
ODSO $(2 \mathrm{~mL} / \mathrm{kg})$

Figure 4. Oral administration effect of ODSO on the total protein (A) and blood sugar (B) levels in normal rats. Values are means $(n=6) \pm$ SEM. NS: Not significant in comparison with the control, ODSO: Opuntia dillenii seeds oil.

\subsubsection{Effect of ODSO on Renal Biomarkers (Uric Acid, Urea, and Creatinine)}

The biomarkers of renal function in the rats were explored after one month of ODSO administration (Figure 5). Daily administration of ODSO by normal rats and at doses of 1 and $2 \mathrm{~mL} / \mathrm{kg}$ for 30 days did not influence the uric acid (A), creatinine (B), and uric acid levels (C) compared always to the control group.

\subsubsection{Effect of ODSO on Change in Body Weight}

The safety of ODSO was also assessed by the change in body weight (Figure 6) during the four weeks of consumption of ODSO ( 1 and $2 \mathrm{~mL} / \mathrm{kg})$ in normal rats. The results showed that the change in body weight in the rats treated with ODSO was similar to that in the control group. 
(A)

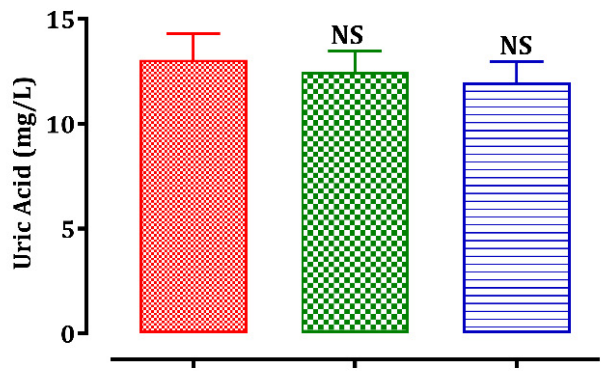

Control
B oDSo $(1 \mathrm{~mL} / \mathrm{kg})$
$\square \operatorname{ODSO}(2 \mathrm{~mL} / \mathrm{kg})$

(B)

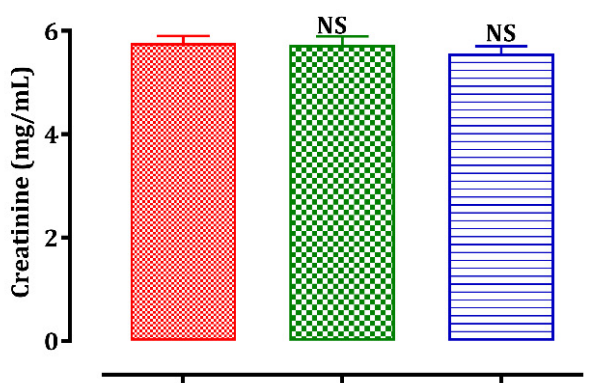

Control

ODSO (1 mL/kg)

$\boxminus$ ODSO (2 mL/kg)

(C)

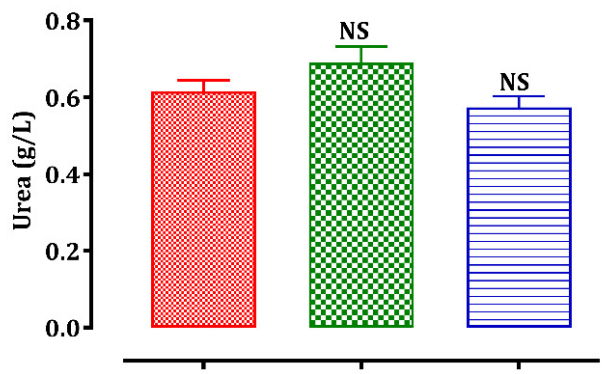

Control

ODSO (1 mL/kg)

$\square$ ODSO (2 mL/kg)

Figure 5. Oral administration effect of ODSO on the level of uric acid (A), creatinine (B), and uric acid $(C)$ in normal rats. Values are means $(n=6) \pm$ SEM. NS: Not significant in comparison with the control, ODSO: Opuntia dillenii seeds oil.

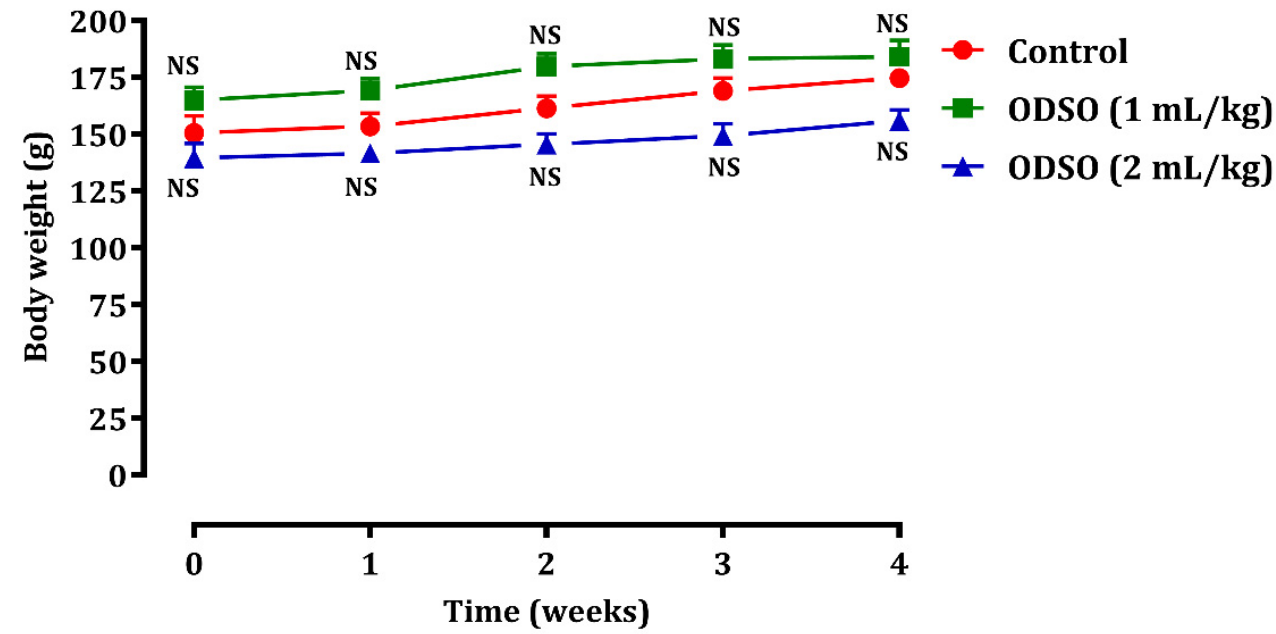

Figure 6. Oral administration effect of ODSO on change in body weight in normal rats. Values are means $(n=6) \pm$ SEM. NS: Not significant in comparison with the control, ODSO: Opuntia dillenii seeds oil. 


\subsection{Effect of the Seed Oil of Opuntia Dillenii on HepG2 Cell Lines}

HepG2 cell lines were used in this study to predict the cytotoxicity of ODSO at various concentrations. (Figure 7). HepG2, the Human-derived liver cells has been widely used to predict mutagenicity, toxicity and carcinogenicity in humans [19]. After $48 \mathrm{~h}$ of incubation with various concentrations of the ODSO, the obtained results showed that cell viability stayed constant, in a dose-dependent way, with increasing concentrations of ODSO. The obtained $\mathrm{IC}_{50}$ was higher than the $400 \mu \mathrm{g} / \mathrm{mL}$. Yosie et al. (2011) consider a substance safe when $\mathrm{IC}_{50}>100 \mu \mathrm{g} / \mathrm{mL}$, while Prayong et al. (2008) consider that a moderate cytotoxicity is when $100 \mu \mathrm{g} / \mathrm{mL}<\mathrm{IC}_{50}<1000 \mu \mathrm{g} / \mathrm{mL}$, and a non-cytotoxicity is when $\mathrm{IC}_{50}>1000 \mu \mathrm{g} / \mathrm{mL}[20,21]$. Consequently, since no IC 50 could be determined by the range of concentrations tested in this work, the ODSO is considered non-cytotoxic in HepG2 cell lines, according to Yosie and his collaborators. Moreover, since the highest concentration studied in this work was $400 \mu \mathrm{g} / \mathrm{mL}$, no conclusion could be taken according to Prayong et al. model.

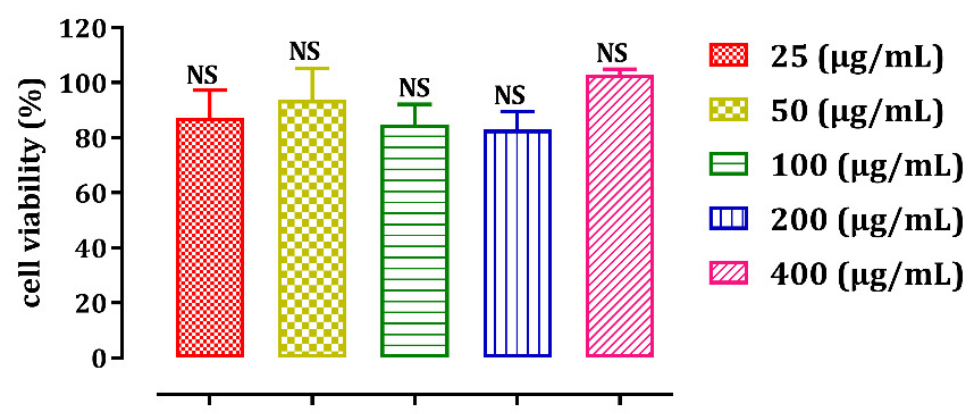

Figure 7. ODSO effect on the viability of HepG2 cells at different concentrations. Values are means \pm SEM. NS: Not significant in comparison with other concentrations.

\subsection{ODSO Stimulating Effect of Glucose Uptake by Isolated Rat Hemidiaphragm In Vitro}

The incubation of the isolated rat hemidiaphragm in Tyrode's solution and the presence of ODSO at a concentration of $1 \mathrm{~g} / \mathrm{L}$ stimulated the uptake of glucose by the isolated rat hemidiaphragm $(53.51 \pm 8.84 \mathrm{mg} / \mathrm{g} / \mathrm{h})$ in comparison with the control group $(26.64 \pm 4.96 \mathrm{mg} / \mathrm{g} / \mathrm{h})$. Moreover, the incubation of the hemidiaphragm in the presence of ODSO $(1 \mathrm{~g} / \mathrm{L})$ and insulin $(4 \mathrm{IU} / \mathrm{mL})$ significantly $(p<0.001)$ increased glucose absorption $(90.50 \pm 12.59 \mathrm{mg} / \mathrm{g} / \mathrm{h})$, compared to the incubated isolated rat hemidiaphragm, only in the presence of ODSO (Figure 8).

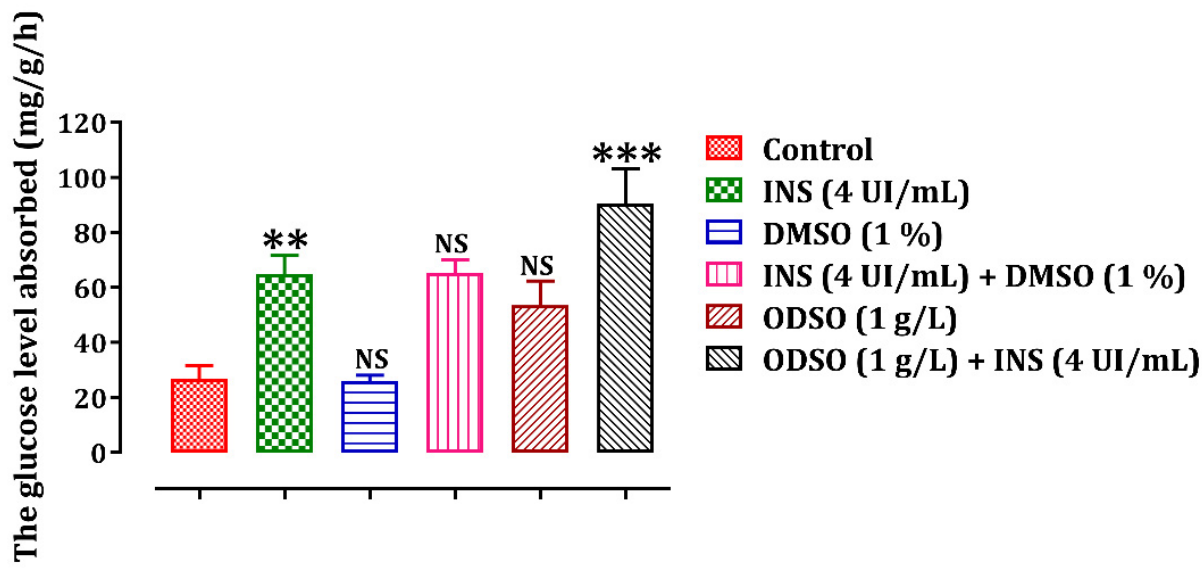

Figure 8. ODSO effect on glucose uptake by isolated rat hemidiaphragm. Values are means $(n=6)$ \pm SEM. ${ }^{* *} p<0.01,{ }^{* * *} p<0.001$ : In comparison with the control group, NS: Not significant in comparison with the control, ODSO: Opuntia dillenii seeds oil; INS: insulin. 


\section{Discussion}

In this study, we began with the acute toxicity test in Swiss albino mice using a dose range to determine essentially the lethal dose $50\left(\mathrm{LD}_{50}\right)$, the maximum tolerable dose, and the observable-effect. After the test period, no mortality or apparent signs of toxicity were noted in treated animals. However, no histological assessments were done since we did not observe any toxicity signs. The absence of acute toxicity risk following the administration of a single dose of oil in mice does not indicate the absence of subacute toxicity. Therefore, the subacute toxicity of ODSO was evaluated in rats at doses of 1 and $2 \mathrm{~mL} / \mathrm{kg}$ in the Wistar rat. This test showed that this antidiabetic plant is not toxic because it did not cause significant variations in biochemical parameters related to kidney and liver function and body weight in ODSO-treated rats. Besides, this oil's safety was also evaluated by studying its effect on the HepG2 cell viability in vitro. The data from this test confirmed this oil's safety, as cell viability was kept constant in the presence of this oil at increasing concentrations. To date, no studies have been conducted on the toxicity of ODSO. However, other studies have been conducted on other species of Opuntia. Indeed, in a study conducted by Berraaouan et al. (2014) to evaluate Opuntia ficus-indica seed oil's toxicity in Albino Swiss mice, it was shown that it was not toxic. After the oral administration or intraperitoneal injection of the oil at various dose $(1,3$, or $5 \mathrm{~mL} / \mathrm{kg})$, and during the 14-day treatment period, no deaths occurred and no abnormal behavioral or autonomous symptoms were found. [22]. In another study, low toxicity of the Opuntia ficus-indica seed oil was shown. The test showed that the lethal doses $\left(\mathrm{LD}_{50}\right)$ are 43 and $2.72 \mathrm{~mL} / \mathrm{kg}$ for the oral administration and the intraperitoneal injection, respectively [23]. From these studies, it can be concluded that the oil of $O$. ficus-indica seeds is not toxic even at high doses. Khémiri et al. (2019) evaluated the $O$. ficus-indica seeds oil's acute toxicity in adult rats, revealing that the oil did not display any signs of toxicity or death in orally administered animals with either a $3.5 \mathrm{~mL}$ dose or a $7 \mathrm{~mL}$ oil $/ \mathrm{kg}$ dose over the five days of the study period [24]. In this study, we also intended to examine the possible mechanism of action for ODSO's antihyperglycemic effect [7], by evaluating this oil's effect on the glucose absorption ability of the isolated rat hemidiaphragm. The measurement of glucose content in the rat hemidiaphragm is a standard and reliable procedure for studying peripheral glucose absorption in vitro [18]. This effect shows that the ODSO statistically augmented the glucose consumption of the isolated rat hemidiaphragm. In a study conducted by Haidara et al., the administration of $\gamma$-tocopherol (a compound present in the ODSO) increased the absorption of glucose into diaphragm muscles [25]. Another study showed that fish oil supplementation in the diet is well associated with a decrease in blood sugar via adjustments in the fatty acid composition of muscle membranes, which can directly or indirectly affect GLUT4 protein levels via regulation of the transcription or translation mechanism [26]. The content of unsaturated fatty acids was high in the ODSO. The sterol fraction was composed of $\beta$ sitosterol, campesterol, and fucosterol. For vitamin E, $\gamma$-tocopherol was present with a low amount [2]. Via a number of pathways, the fatty acid content of membranes may affect the behavior of membrane proteins involved in glucose transport. Borkman et al. demonstrated that the poly-fatty acid long-chain unsaturated phospholipid content of muscle membranes may affect insulin action through the effects of their physical properties on proteins such as insulin receptors and glucose transporters [27]. It has previously been demonstrated that diets high in polyunsaturated fatty acids promote glucose transport in cells and that improvements in the physicochemical microenvironments of lipid domain membranes correlated with glucose transporters influence insulin action. This modification can involve an improvement in muscle tissue membrane fluidity, which enhances or promotes the penetration of glucose carriers through the membrane. Fatty acids have been shown to regulate the glucose transport pathway physiologically [28]. A study conducted by Pu et al. demonstrated that acute exposure of L6 muscle cells to palmitic acid significantly stimulates glucose uptake via two distinct signaling pathways (PI3K/AMPK/Akt and PI3K/ERK), inducing an increase in translocated GLUT4 at the membrane surface [29]. However, the mixture of ODSO and insulin significantly augmented the glucose consumption activity 
of the isolated rat hemidiaphragm. In addition, these results agree with those of Saleh et al. which showed that olive oil supplementation to ovariectomized rats resulted in an enhancement of insulin-stimulated glucose uptake by diaphragm [30]. It appears that synergy may have occurred between ODSO and insulin when tested together. It can be concluded that ODSO improves hyperglycemia by an extra-pancreatic mechanism, and improves the effect of insulin on glucose absorption in the isolated rat hemidiaphragm [31]. Insulin has been documented to promote glucose transfer in the isolated rat diaphragm, mainly by translocating active glucose transport units from the intracellular membrane area to the plasma membrane [32]. Polyunsaturated fatty acids improved glucose capture after palmitic acid-induced insulin resistance in L6 muscle cells. Linoleic and $\alpha$-linolenic acids strengthen glucose capture by $\mathrm{C} 2 \mathrm{C} 12$ muscle cells that have been insulin resistant due to palmitic acid [33]. These results imply that the ODSO contains active compounds that, when combined with insulin at some concentration, enhance its influence. As a result, an improvement in glucose peripheral intake may be a factor involved in the antihyperglycemic behavior shown in the current research [34].

\section{Materials and Methods}

\subsection{Chemicals, Reagents, and Materials}

The following drugs and solvents were used in this study: $\mathrm{D}(+)$-glucose anhydrous, which was purchased from Sigma Aldrich (Riedel-de Haen, Germany). Dimethyl-sulfoxide, sodium pentobarbital was purchased from Ceva Santé Animale (Paris, France), and glucose GOD-POD kit was purchased from Biosystems (Barcelone, Spain). Alanine aminotransferase (ALT), total bilirubin, direct bilirubin, aspartate aminotransferase (AST), alkaline phosphatase (ALP), total cholesterol, triglycerides, HDL, LDL, total protein, urea, creatinine, and uric acid kits were purchased from Biosystems, Spain. Insulin was purchased from the pharmacy (Cooper Pharma Company, Morocco). All chemicals were of analytical grade.

\subsection{Collecting and Identifying Plant Material}

In February 2018, Opuntia dillenii (Ker-Gawl) haw. freshly collected fruits from the region of Essaouira (Latitude: $31^{\circ} 30^{\prime} 45.00^{\prime \prime}$ N Longitude: $-9^{\circ} 46^{\prime} 12.00^{\prime \prime} \mathrm{W}$ ), Morocco, were used as plant material in this study. Their identification was made by Professor Mohammed Fennan, a botanical expert from Mohammed V University's scientific institute. The specimen was stored under the number HUMPOM 351 at the herbarium of the University of Mohammed First, Oujda, Morocco.

\subsection{Preparation of the Seeds}

The seeds were being separated from $O$. dillenii fruits after being mashed. They were well cleaned with distilled water and, after being air-dried, they were ground using an electric grinder to get a fine and homogeneous powder. This final powder was stored $\left(-20^{\circ} \mathrm{C}\right)$ until further use.

\subsection{Seeds Oil Extraction}

A total of $500 \mathrm{~mL}$ of petroleum ether was mixed to $100 \mathrm{~g}$ of the previously prepared seed powder to separate the seeds' oil (repeated 2 times). The mixture was stirred for $24 \mathrm{~h}$ at room temperature. A rotary evaporator was used after filtration to get rid of the solvent. The oil was collected and stored at $4{ }^{\circ} \mathrm{C}$.

\subsection{Animals}

This study was conducted on Swiss albino mice and Wistar rats (male and female). The animals were reared at the Department of Biology of the Faculty of Science of Oujda (a photoperiod of $12 \mathrm{~h}$ of light $/ 12 \mathrm{~h}$ of darkness and temperature of $22+2{ }^{\circ} \mathrm{C}$ ). The animals were kept under favorable conditions of rearing with free access to water and food. 


\subsection{Acute Toxicity}

Acute toxicity was evaluated intraperitoneally on albino mice, weighing 22-32 g. Thirty mice have been regrouped into five lots $\left(n=6 ; \sigma^{7} / q=1\right)$, then treated by raising doses of $\operatorname{ODSO}(1,3,5$, and $7 \mathrm{~mL} / \mathrm{kg})$ or distilled water $(10 \mathrm{~mL} / \mathrm{kg})$. The signs of toxic effects and/or mortality have been observed after $2 \mathrm{~h}$ and every $24 \mathrm{~h}$ during 14 days after administration.

\subsection{Subacute Toxicity Study of Opuntia Dillenii Seed Oil in Rats \\ 4.7.1. Grouping Rats}

The normal rats weighing between 200 and $250 \mathrm{~g}$ were grouped into 3 groups $(n=6$; $\left.\sigma^{7} / q=1\right)$. The control group received only the distilled water at the dose of $10 \mathrm{~mL} / \mathrm{kg}$, and the treated groups received the ODSO at the dose of 1 or $2 \mathrm{~mL} / \mathrm{kg}$.

\subsubsection{Test Procedure}

During this study, the oil was administered to rats with oral gavage once a day for four weeks. Moreover, the bodyweight of the rats was measured weekly. At the end of this treatment period, the rats have fasted for $14 \mathrm{~h}$. Then they were subjected to anesthesia, and the blood was collected by cardiac puncture and immediately centrifuged at $3000 \mathrm{rpm}$ for $10 \mathrm{~min}$. The plasma was then stored at $-20^{\circ} \mathrm{C}$ for biochemical analyses.

\subsubsection{Assays of Biochemical Parameters}

Several biochemical parameters have been measured in plasma. Aspartate aminotransferase, alanine aminotransferase, alkaline phosphatase, bilirubin (total and direct), plasma glucose, total protein, urea, creatinine, uric acid, total cholesterol, triglycerides (TG), high-density lipoproteins (HDL-c), and low-density lipoproteins (LDL-c). All tests were performed with the COBAS INTEGRA ${ }^{\circledR} 400$-Plus analyzer, using standard clinical diagnostic kits.

\subsection{Study of the Cytotoxicity of the Seed Oil of Opuntia dillenii \\ 4.8.1. Culture of Cell Lines}

The human hepatoma HepG2 cell lines were used to evaluate the cytotoxic activity of the extract. The cells were grown in $75 \mathrm{~cm}^{3}$ flasks, containing Dulbecco's modified Eagle medium (DMEM) culture medium supplemented with $10 \%$ fetal calf plasma (FCS) and antibiotics (a mixture of penicillin $(100 \mathrm{U} / \mathrm{mL})$ and streptomycin $(100 \mathrm{U} / \mathrm{mL}))$, at $37^{\circ} \mathrm{C}$ in a sterile oven and a humid atmosphere saturated with $5 \% \mathrm{CO}_{2}$. After incubation, the cell layer was rinsed with $10 \mathrm{~mL}$ of phosphate-buffered saline $\left(37^{\circ} \mathrm{C}\right)$, then bathed in $2 \mathrm{~mL}$ of trypsin $((0.5 \mathrm{mg} / \mathrm{mL})+$ EDTA $(0.2 \mathrm{mg} / \mathrm{mL}))$. After trypsinization, the flasks were incubated at $37^{\circ} \mathrm{C}$ for 4 to $5 \mathrm{~min}$. The action of the trypsin was then stopped by adding $10 \mathrm{~mL}$ of supplemented culture medium.

\subsubsection{Evaluation of Cell Viability by the MTT Test}

The HepG2 cells were diluted in the medium to have a seeding concentration of 3500 cells per well, then they were introduced into 96-well microplates (100 $\mu \mathrm{L} /$ well). After $48 \mathrm{~h}$ of incubation $\left(37^{\circ} \mathrm{C}, 5 \% \mathrm{CO}_{2}\right)$, the cells can be treated if they are in the exponential growth phase (between $80 \%$ and $90 \%$ confluence). The ODSO was solubilized in DMSO then diluted in a hot medium to have a concentration of $400 \mu \mathrm{g} / \mathrm{mL}$. A series of dilutions were then carried out in microplates to obtain the following concentrations-400, 200, 100, 50 , and $25 \mu \mathrm{g} / \mathrm{mL}$. The culture medium is removed from the cell culture microplates and replaced with $100 \mu \mathrm{L}$ of each dilution. Four repetitions were performed on each concentration tested, and a solvent control was also tested in four replications. The microplates were incubated for $48 \mathrm{~h}$ at $37^{\circ} \mathrm{C}, 5 \% \mathrm{CO}_{2}$. The medium was then removed and replaced with a solution of MTT at $0.5 \mathrm{mg} / \mathrm{mL}$ in complete DMEM medium $(100 \mu \mathrm{L} /$ well $)$ for at least 1 $\mathrm{h}$ and $30 \mathrm{~min}$ at $37^{\circ} \mathrm{C}$. The MTT solution was then removed, and the insoluble formazan crystals formed at the bottom of the wells were dissolved in pure DMSO $(100 \mu \mathrm{L} /$ well $)$. 
After a gentle stirring, the absorbance was measured at $550 \mathrm{~nm}$. Knowing that the solvent control corresponds to $100 \%$ cell viability, the following formula was used to calculate the percentage of cell viability:

$\%$ Cell viability $=\left(\mathrm{OD}_{\mathrm{avg}}\right.$ cells treated $/ \mathrm{OD}_{\mathrm{avg}}$ control cells $) \times 100 \pm \mathrm{SD}$

$\mathrm{OD}_{\text {avg }}$ cells treated: Average optical density of the 4 repetitions of each concentration. $\mathrm{OD}_{\mathrm{avg}}$ control cells: Average optical density of the 4 repetitions of the blank (solvent). SD: Standard deviation.

\subsection{Study of the Stimulatory Effect of the Absorption of Glucose by the Isolated Rat Hemidiaphragm}

4.9.1. Grouping of Animals

Wistar rats weighing between 200 and $300 \mathrm{~g}$ were used in this experiment. These rats were left on an empty stomach for $36 \mathrm{~h}$ before handling to consume all the glucose stored in the hemidiaphragm and therefore to avoid the release of glucose from the hemidiaphragm into the incubation medium. The rats were separated into 6 groups $\left(n=6 ; 0^{\pi} / q=1\right)$.

Control: Incubation in Tyrode's glucose solution $(1 \mathrm{~g} / \mathrm{L})$.

INS (4 IU/mL): Incubation in Tyrode's glucose solution $(1 \mathrm{~g} / \mathrm{L})+$ insulin $(4 \mathrm{IU} / \mathrm{mL})$. DMSO (1\%): Incubation in Tyrode's glucose solution $(1 \mathrm{~g} / \mathrm{L})+$ DMSO $(1 \%)$.

INS (4 IU/mL) + DMSO (1\%): Incubation in Tyrode's glucose solution $(1 \mathrm{~g} / \mathrm{L})+$ insulin $(4 \mathrm{IU} / \mathrm{mL})+$ DMSO $(1 \%)$.

ODSO (1 g/L): Incubation in Tyrode's glucose solution $(1 \mathrm{~g} / \mathrm{L})+\operatorname{ODSO}(1 \mathrm{~g} / \mathrm{L})$.

ODSO $(1 \mathrm{~g} / \mathrm{L})+$ INS $(4 \mathrm{IU} / \mathrm{mL})$ : Incubation in Tyrode's glucose solution $(1 \mathrm{~g} / \mathrm{L})+$ ODSO $(1 \mathrm{~g} / \mathrm{L})+$ insulin $(4 \mathrm{IU} / \mathrm{mL})$.

\subsubsection{Experimental Design}

Peripheral glucose uptake from rat hemidiaphragm was estimated according to the method described by Bnouham et al. [34]. Initially, the rat fasted $36 \mathrm{~h}$ were anesthetized slightly, followed by cervical dislocation. Once in total anesthesia (7-10 min), an incision at the abdominal wall is performed. Afterward, the hemidiaphragm is dissected, avoiding any trauma or destruction of this muscle. Then, the diaphragm is placed in a petri dish filled with cold, glucose-free Tyrode solution ( $\mathrm{NaCl}, 134 \mathrm{mM} ; \mathrm{KCl}, 2.68 \mathrm{mM} ; \mathrm{CaCl}_{2}, 1.80 \mathrm{mM}$; $\mathrm{MgCl}_{2}, 1.05 \mathrm{mM} ; \mathrm{NaH}_{2} \mathrm{PO}_{4}, 417 \mu \mathrm{M} ; \mathrm{NaHCO}_{3}, 11.9 \mathrm{mM}$; Glucose, $\left.5.56 \mathrm{mM}\right)$ to wash it off any debris and cut it into two equal pieces. Immediately after cutting, each hemidiaphragm is placed in a tube filled with $10 \mathrm{~mL}$ of the Tyrode solution in which the product to be tested is solubilized. The tube is incubated in a married bath for $1 \mathrm{~h}$ and at $37{ }^{\circ} \mathrm{C}$, leaving the continuous oxygenation passage $\left(95 \% \mathrm{O}_{2}, 5 \% \mathrm{CO}_{2}\right)$ and under 120 cycles $/ \mathrm{min}$ agitation. At the end of incubation, the isolated rat hemidiaphragm was removed, dried in the oven for $8 \mathrm{~h}\left(37^{\circ} \mathrm{C}\right)$, and weighed (dry weight). The glucose contained in solutions was dosed using a commercial enzyme dosing kit (GLUCOSE, Biosystems) based on the GOD-POD method (Glucose oxidase and peroxidase). Glucose absorbed by the isolated rat hemidiaphragm is expressed in milligrams of glucose absorbed per gram of dry hemidiaphragm for one hour $(\mathrm{mg} / \mathrm{g} / \mathrm{h})$.

\subsection{Statistical Analyses}

The study results were expressed as mean \pm SEM, and the difference between the groups was calculated by one-way analysis of variance (ANOVA) using GraphPad Prism 7 for windows. The difference was considered significant when $p<0.05$.

\section{Conclusions}

In conclusion, the toxicity investigation results confirm the safety of the Opuntia dillenii seed oil when used to treat diabetes. Moreover, the antihyperglycemic property of this oil can be thought an increase in glucose consumption by the diaphragm. Therefore, this oil could be beneficial to diabetic patients thanks to its hypoglycemic effect, to prevent or 
treat chronic hyperglycemia that causes the onset of diabetic complications. Lastly, further experiments are warranted to identify the active compounds and the mechanism of activity of this effect.

Author Contributions: Conceptualization, M.B. (Mohamed Bouhrim) and M.B. (Mohamed Bnouham); methodology, B.E.; software, S.B.; validation, A.B., A.Z., H.M (Hassane Mekhfi). and A.L.; formal analysis, L.K.; data curation, M.A.; writing-original draft preparation, M.B. and H.M. (Hamza Mechchate); review and editing, O.M.A.K. supervision, M.B. (Mohamed Bnouham). All authors have read and agreed to the published version of the manuscript.

Funding: This research was funded by the Deanship of Scientific Research at Princess Nourah bint Abdulrahman University through the Fast-track Research Funding Program.

Institutional Review Board Statement: The study was conducted according to the guidelines of the Declaration of Helsinki and approved by the Institutional Review Board of the Faculty of Sciences, Oujda, Morocco (39/19-LBBEH-04 and 14/11/2019).

Informed Consent Statement: Not applicable.

Data Availability Statement: Data are available upon reasonable request.

Acknowledgments: The authors are thankful to the Deanship of Scientific Research at Princess Nourah bint Abdulrahman University for the support of this research through the Fast-Track Research Funding Program.

Conflicts of Interest: The authors declare no conflict of interest.

Sample Availability: Samples of the compounds are available from the authors.

\section{References}

1. Sharma, C.; Rani, S.; Kumar, B.; Kumar, A.; Raj, V.; Vihar, V. Plant Opuntia Dillenii: A Review on It's Traditional Uses, Phytochemical and Pharmacological Properties. Pharm. Sci. 2015, 1, $29-43$.

2. Ghazi, Z.; Ramdani, M.; Fauconnier, M.L.; El Mahi, B.; Cheikh, R. Fatty Acids Sterols and Vitamin e Composition of Seed Oil of Opuntia Ficus Indica and Opuntia Dillenii from Morocco. J. Mater. Environ. Sci. 2013, 4, 967-972.

3. Karabagias, V.K.; Karabagias, I.K.; Gatzias, I.; Badeka, A.V. Prickly Pear Seed Oil by Shelf-Grown Cactus Fruits: Waste or Maste? Processes 2020, 8, 132. [CrossRef]

4. Aragona, M.; Lauriano, E.R.; Pergolizzi, S.; Faggio, C. Opuntia ficus-indica (L.) Miller as a Source of Bioactivity Compounds for Health and Nutrition. Nat. Prod. Res. 2018, 32, 2037-2049. [CrossRef]

5. Ghazi, Z.; Ramdani, M.; Tahri, M.; Rmili, R.; Elmsellem, H.; El Mahi, B.; Fauconnier, M.L. Chemical Composition and Antioxidant Activity of Seeds Oils and Fruit Juice of Opuntia Ficus Indica and Opuntia Dillenii from Morocco. J. Mater. Environ. Sci. 2015, 6, 2321-2327.

6. Bouhrim, M.; Ouassou, H.; Choukri, M.; Mekhfi, H.; Ziyyat, A.; Legssyer, A.; Aziz, M.; Bnouham, M. Hepatoprotective Effect of Opuntia Dillenii Seed Oil on CCl4 Induced Acute Liver Damage in Rat. Asian Pac. J. Trop. Biomed. 2018, 8, 254-260. [CrossRef]

7. Bouhrim, M.; Ouassou, H.; Loukili, E.; Ramdani, M.; Mekhfi, H.; Ziyyat, A.; Legssyer, A.; Aziz, M.; Bnouham, M. Antidiabetic Effect of Opuntia Dillenii Seed Oil on Streptozotocin-Induced Diabetic Rats. Asian Pac. J. Trop. Biomed. 2019, 9, 381-388. [CrossRef]

8. Bouhrim, M.; Daoudi, N.E.; Ouassou, H.; Benoutman, A.; Loukili, E.H.; Ziyyat, A.; Mekhfi, H.; Legssyer, A.; Aziz, M.; Bnouham, M. Phenolic Content and Antioxidant, Antihyperlipidemic, and Antidiabetogenic Effects of Opuntia Dillenii Seed Oil. Sci. World J. 2020, 2020, 1-8. [CrossRef] [PubMed]

9. Dias, D.A.; Urban, S.; Roessner, U. A Historical Overview of Natural Products in Drug Discovery. Metabolites 2012, 2, 303-336. [CrossRef]

10. Es-Safi, I.; Mechchate, H.; Amaghnouje, A.; Jawhari, F.Z.; Bari, A.; Cerruti, P.; Avella, M.; Andriy, A.; Andriy, D. Medicinal Plants Used to Treat Acute Digestive System Problems in the Region of Fez-Meknes in Morocco: An Ethnopharmacological Survey. Ethnobot. Res. Appl. 2020, 20. [CrossRef]

11. Ugwah-Oguejiofor, C.J.; Okoli, C.O.; Ugwah, M.O.; Umaru, M.L.; Ogbulie, C.S.; Mshelia, H.E.; Umar, M.; Njan, A.A. Acute and Sub-Acute Toxicity of Aqueous Extract of Aerial Parts of Caralluma Dalzielii NE Brown in Mice and Rats. Heliyon 2019, 5, e01179. [CrossRef]

12. Jamil, F.; Mostaf, E. An Overview on Ethnobotanico-Pharmacological Studies Carried out in Morocco, from 1991 to 2015 : Systematic Review (Part 1). J. Ethnopharmacol. 2020, 267, 113200.

13. Elachouri, M. Ethnobotany/ethnopharmacology, and bioprospecting: Issues on knowledge and uses of medicinal plants by Moroccan people. In Natural Products and Drug Discovery; Elsevier: Amsterdam, The Netherlands, 2018; pp. $105-118$. 
14. Es-safi, I.; Mechchate, H.; Amaghnouje, A.; Jawhari, F.Z.; Al Kamaly, O.M.; Imtara, H.; Grafov, A.; Bari, A.; Bousta, D. An Insight into the Anxiolytic and Antidepressant-Like Proprieties of Carum carvi L. and Their Association with Its Antioxidant Activity. Life 2021, 11, 207. [CrossRef]

15. Denny, K.H.; Stewart, C.W. Acute, subacute, subchronic, and chronic general toxicity testing for preclinical drug development. In A Comprehensive Guide to Toxicology in Nonclinical Drug Development; Elsevier: Amsterdam, The Netherlands, 2017 ; pp. $109-127$.

16. Bnouham, M.; Mekhfi, H.; Legssyer, A.; Ziyyat, A. Ethnopharmacology Forum Medicinal Plants Used in the Treatment of Diabetes in Morocco. Int. J. Diabetes Metab. 2002, 10, 33-50.

17. Abinaya, R.; Peter, S.J.; Shalini, M.; Sabina, E.P. Prevalence of Diabetes Mellitus and Herbal Medication. J. Pharm. Sci. Res. 2020, $12,720-729$.

18. Sandhya Rani, M.; Pippalla, R.S.; Krishna Mohan, G.; Raju, A.B.; Harish Kumar, V. In Vitro Study of Methanolic Extracts of Dodonaea Viscosa. Linn and Wrightia Tinctoria R. Br. on Glucose Uptake by Isolated Rat Hemi- Diaphragm. Int. J. Chem. Sci. 2012, 10, 1724-1730.

19. Liu, Z.H.; Zeng, S. Cytotoxicity of Ginkgolic Acid in HepG2 Cells and Primary Rat Hepatocytes. Toxicol. Lett. 2009, 187, 131-136. [CrossRef]

20. Yosie, A.; Effendy, M.A.W.; Sifzizul, T.M.T.; Habsah, M. Antibacterial, Radical-Scavenging Activities and Cytotoxicity Properties of Phaleria Macrocarpa (Scheff.) Boerl. Leaves in Hepg2 Cell Lines. Int. J. Pharm. Sci. Res. 2011, 2, 1693.

21. Prayong, P.; Barusrux, S.; Weerapreeyakul, N. Cytotoxic Activity Screening of Some Indigenous Thai Plants. Fitoterapia 2008, 79, 598-601. [CrossRef]

22. Berraaouan, A.; Abderrahim, Z.; Abdelkhaleq, L.; Mohammed, A.; Mohamed, B. Evaluation of Protective Effect of Cactus Pear Seed Oil (Opuntia ficus-indica L. MILL.) against Alloxan- Induced Diabetes in Mice. Asian Pac. J. Trop. Med. 2015, 8, 532-537. [CrossRef] [PubMed]

23. Boukeloua, A.; Belkhiri, A.; Djerrou, Z.; Bahri, L.; Boulebda, N.; Pacha, Y.H. Acute toxicity of opuntia ficus indica and pistacia lentiscus seed oils in mice. Afr. Netw. Ethnomed. 2012, 9, 607-611.

24. Khémiri, I.; Bitri, L. Effectiveness of Opuntia Ficus Indica L. Inermis Seed Oil in the Protection and the Healing of Experimentally Induced Gastric Mucosa Ulcer. Oxidative Med. Cell. Longev. 2019, 2019. [CrossRef] [PubMed]

25. Haidara, M.A.; Ibrahim, I.M.; Al-Tuwaijri, A.S.; Awadalla, S.A.; Yaseen, H. Effect of $\alpha$-Tocopherol on Glucose Uptake and Contractility in Rat Skeletal Muscle. Med. Sci. Monit. 2003, 9, BR174-BR177.

26. Girón, M.D.; Salto, R.; Hortelano, P.; Periago, J.L.; Vargas, A.M.; Suárez, M.D. Increased Diaphragm Expression of GLUT4 in Control and Streptozotocin-diabetic Rats by Fish Oil-supplemented Diets. Lipids 1999, 34, 801-807. [CrossRef]

27. Borkman, M.; Storlien, L.H.; Pan, D.A.; Jenkins, A.B.; Chisholm, D.J.; Campbell, L.V. The Relation between Insulin Sensitivity and the Fatty-Acid Composition of Skeletal-Muscle Phospholipids. N. Engl. J. Med. 1993, 328, 238-244. [CrossRef]

28. Long, S.D.; Pekala, P.H. Regulation of GLUT4 Gene Expression by Arachidonic Acid: Evidence for Multiple Pathways, One of Which Requires Oxidation to Prostaglandin E2. J. Biol. Chem. 1996, 271, 1138-1144. [CrossRef] [PubMed]

29. Pu, J.; Peng, G.; Li, L.; Na, H.; Liu, Y.; Liu, P. Palmitic Acid Acutely Stimulates Glucose Uptake via Activation of Akt and ERK1/2 in Skeletal Muscle Cells. J. Lipid Res. 2011, 52, 1319-1327. [CrossRef]

30. Saleh, N.K.; Saleh, H.A. Olive Oil Improved the Impairment of in Vitro Insulin-Stimulated Glucose Uptake by Diaphragm in Ovariectomized Female Wistar Rats. Exp. Gerontol. 2010, 45, 964-969. [CrossRef]

31. Uddin, S.; Islam, M.M.; Hassan, M.M.; Bhowmik, A.; Rokeya, B. Amaranthus Viridis Modulates Anti-Hyperglycemic Pathways in Hemi-Diaphragm and Improves Glycogenesis Liver Function in Rats. J. Pharmacogn. Phytother. 2016, 8, 73-181. [CrossRef]

32. Wardzalas, L.J.; Jeanrenaud, B. Potential Mechanism of Insulin Action on Glucose Transport in the Isolated Rat Diaphragm. Apparent Translocation of Intracellular Transport Units to the Plasma Membrane. J. Biol. Chem. 1981, 256, 7090-7093. [CrossRef]

33. Sawada, K.; Kawabata, K.; Yamashita, T.; Kawasaki, K.; Yamamoto, N.; Ashida, H. Ameliorative Effects of Polyunsaturated Fatty Acids against Palmitic Acid-Induced Insulin Resistance in L6 Skeletal Muscle Cells. Lipids Health Dis. 2012, 11, 36. [CrossRef] [PubMed]

34. Bnouham, M.; Merhfour, F.Z.; Ziyyat, A.; Aziz, M.; Legssyer, A.; Mekhfi, H. Antidiabetic Effect of Some Medicinal Plants of Oriental Morocco in Neonatal Non-Insulin-Dependent Diabetes Mellitus Rats. Hum. Exp. Toxicol. 2010, 29, 865-871. [CrossRef] [PubMed] 